Artículo científico

Volumen 30(2):437-446. Mayo-agosto, 2019

e-ISSN 2215-3608, doi:10.15517/am.v30i1.34916

https://revistas.ucr.ac.cr/index.php/agromeso/index

\title{
Evaluación de dos sistemas de sexado en plantas de papaya (Carica papaya) híbrido Pococí ${ }^{1}$
}

\author{
Evaluation of two-sex determining systems in papaya plants (Carica papaya) Pococí \\ hybrid
}

\author{
Walter Barrantes-Santamaría ${ }^{2}$, Carlos Loría-Quirós ${ }^{3}$,Luis Gómez-Alpízar ${ }^{4}$
}

1 Recepción: 24 de octubre, 2018. Aprobación: 14 de enero, 2019. Este trabajo formó parte de proyectos presentados en la Vicerrectoría de Investigación de la Universidad de Costa Rica por parte del programa de Fruticultura de la Estación Experimental Fabio Baudrit y del Laboratorio de Cultivo de tejidos del Centro de Investigaciones Agronómicas.

2 Universidad de Costa Rica, Estación Experimental Fabio Baudrit, Programa de Recursos Fitogenéticos. Apdo. postal 183-4050. Alajuela, Costa Rica. walter.barrantes@ucr.ac.cr (autor para correspondencia; https://orcid.org/0000-0002-5288-451X).

3 Universidad de Costa Rica, Estación Experimental Fabio Baudrit, Programa de Fruticultura. Apdo.postal 183-4050. Alajuela, Costa Rica. carlos.loria@ucr.ac.cr

4 Universidad de Costa Rica, Escuela de Agronomía, Ciudad Universitaria Rodrigo Facio. Apdo. postal 2060. San José, Costa Rica. luis. gomezalpizar@ucr.ac.cr

\section{Resumen}

Introducción. Los productores de papaya prefieren plantas hermafroditas por las características de sus frutos; pero deben esperar hasta el inicio de la floración para identificar y seleccionar las plantas. Actualmente, es posible determinar el sexo de las plantas de papaya en estado de plántula mediante marcadores moleculares. Objetivo. El objetivo de esta investigación fue comparar el crecimiento vegetativo y productivo de plantas de papaya híbrido Pococí, sexadas mediante dos sistemas: convencional (SC) y molecular (SM). Materiales y métodos. Para el sistema de sexado convencional se empleó el método tradicional de siembra de los agricultores, que consiste en plantar tres plántulas y determinar el sexo por inspección visual, eliminar las plantas femeninas y dejar una planta hermafrodita por sitio de siembra. En el sistema de sexado molecular se determinó el sexo en el almácigo con base en marcadores moleculares y luego se estableció una planta hermafrodita por sitio de siembra. El ensayo se realizó en la finca de un productor de papaya localizada en la Rita de Guápiles, provincia de Limón, Costa Rica, entre marzo y octubre del año 2010. Resultados. No se observaron diferencias significativas para altura de planta y diámetro de tallo con ambos sistemas de sexado, lo que indica que el periodo de competencia inicial a que fueron sometidas las plántulas en el sistema de SC no afectó el desarrollo vegetativo. Para las variables productivas, se encontraron diferencias significativas entre ambos sistemas de sexado. Las plantas con SM presentaron floración y cuaje de frutos a más temprana edad. La producción total y la calidad de fruta fueron similares entre ambos tratamientos. Conclusión. El sistema de sexado no influyó sobre el crecimiento, desarrollo y rendimiento de las plantas bajo las condiciones de este estudio, lo que indica la posibilidad de utilizar plantas SM para el cultivo del híbrido Pococí.

Palabras clave: características agronómicas, rendimiento de cultivo, frutas tropicales, determinación del sexo.

\footnotetext{
Abstract

Introduction. Papaya growers prefer hermaphrodite plants for their fruit characteristics, but they must wait until the beginning of flowering to identify and select plants. Currently, it is possible to determine the sex of papaya plants 
in the seedling stage using molecular markers. Objective. The objective of this research was to compare the vegetative and productive growth of papaya plants Pococí hybrid, sexed by two systems: conventional (CS) and molecular (MS). Materials and methods. For the conventional sexing system the traditional method of farmers sowing was used, which consists of planting three seedlings and determine the sex by visual inspection, eliminate female plants and leave a hermaphrodite plant per sowing site. In the molecular sexing system, sex was determined in the seedbed based on the molecular markers, and then a hermaphrodite plant was established per planting site. The trial was conducted on the farm of a papaya producer located in the Rita de Guapiles, Limon province, Costa Rica, between March and October of 2010. Results. No significant differences were observed for plant height and stem diameter with both sexing systems, indicating that the period of initial competition to which the seedlings were subjected in the SC system did not affect vegetative development. For the productive variables, significant differences were found between both sexing systems. SM plants presented flowering and fruit set at an earlier age. The total production and fruit quality were similar between both treatments. Conclusion. The sex-determining procedure did not influence the growth, development, and yield of the plants under this study condition, which indicates the possibility of using SM plants for cultivation of the Pococí hybrid.

Keywords: Agronomic characteristics, crop performance, tropical fruits, sex determination.

\section{Introducción}

La papaya (Carica papaya L.) es una especie trioica, debido a que las plantas adultas presentan tres posibles formas sexuales: masculinas, femeninas y hermafroditas (Jiménez et al., 2014). A nivel comercial, los productores de papaya prefieren las plantas hermafroditas por varias razones, a saber, los frutos de las plantas hermafroditas tienen forma alargada, lo que favorece su comercialización al requerir contenedores de menor volumen, además, presentan una menor cavidad donde se localizan las semillas (mayor relación pulpa cavidad en comparación con los frutos de plantas femeninas) y mayor firmeza, que contribuye a menores daños poscosecha (Mora y Bogantes, 2004).

La semilla proveniente del cruzamiento de una planta femenina por una hermafrodita produce descendientes con una relación hermafroditas a hembras de 1:1 (50 \% cada tipo sexual) (Hueso et al., 2015). El híbrido Pococí es actualmente el más cultivado en Costa Rica, el cual se caracteriza por ser homogéneo y de alto rendimiento, con una fruta de buen sabor, cuyo peso varía entre 1 y 1,5 kg (Bogantes y Mora, 2006). La semilla de este híbrido presenta una proporción 1:1 entre ambos sexos. Sin embargo, en algunas ocasiones el porcentaje de plantas hermafroditas del híbrido Pococí disminuye hasta un 40 \%, por razones aún en investigación (Bogantes et al., 2011).

El sexo de las plantas de papaya es determinado, por métodos convencionales, hasta que las plantas llegan a floración (entre dos a tres meses después de la siembra) (Aspeitia, 2012). Cuando aparecen las primeras flores, los productores determinan el sexo de las plantas y eliminan las femeninas, de manera que permanezcan solo las hermafroditas en el campo. Este sistema es poco eficiente en el uso del tiempo, material de siembra (plántulas), mano de obra y nutrimentos, al descartar un número considerable de plantas al momento del sexado (Fitch et al., 2005a; 2005b; Salinas et al., 2018). Adicionalmente, en este sistema, no es posible alcanzar un $100 \%$ de los puntos de siembra con plantas hermafroditas. En el híbrido Pococí, la siembra de tres a cuatro plantas por sitio resulta en un 88 , $5 \%$ y $94,3 \%$ de plantas hermafroditas, respectivamente, por razones aún en investigación. En ocasiones el porcentaje de plantas hermafroditas del híbrido Pococí disminuye hasta un $40 \%$, por lo cual con tres plantas por punto de siembra se obtiene un $78,5 \%$ de plantas hermafroditas, y con cuatro plantas un $87 \%$; de manera que, entre un $21,5 \%$ y un 5,7 $\%$ de los puntos de siembra es ocupado por plantas femeninas, lo que reduce el área productiva (Bogantes et al., 2011).

Los avances de la biología molecular han hecho posible la determinación temprana y rápida del sexo de las plántulas de papaya, mediante marcadores moleculares y la técnica de la reacción en cadena de la polimerasa (PCR 
por sus siglas en inglés) (Deputy et al., 2002; Urasaki et al., 2002a; 2002b; Sánchez y Núñez, 2008; Saalau et al., 2009; Posada et al., 2015). Estos métodos han estado disponibles por más de quince años, pero solo dos estudios, uno en Hawaii (Fitch et al., 2005a; 2005b) y otro en España (Salinas et al., 2018), han comparado el crecimiento y rendimiento de plantas de papaya sexadas molecularmente con plantas sexadas por el método convencional.

Esta investigación tuvo como objetivo comparar el crecimiento, vegetativo y reproductivo de plantas de papaya híbrido Pococí sexadas mediante dos sistemas: convencional (SC) y molecular (SM).

\section{Materiales y Métodos}

El estudio se realizó en una finca de un productor de papaya, ubicada en la Rita en el Cantón de Pococí, provincia de Limón, Costa Rica. Cuyas coordenadas son latitud $10^{\circ} 12^{\prime} 56^{\prime \prime} \mathrm{N}$ y longitud $83^{\circ} 47^{\prime} 32^{\prime \prime} \mathrm{O}$. Esta región se caracteriza por presentar un clima tropical lluvioso con una temperatura que varía entre 24 y $32{ }^{\circ} \mathrm{C}$, una precipitación promedio anual de $4290 \mathrm{~mm}$ y una altitud $260 \mathrm{msnm}$. El periodo experimental comprendió los meses de marzo a octubre del año 2010.

\section{Material vegetal}

Las plantas de papaya (Carica papaya L.) evaluadas fueron del híbrido comercial para fruta fresca Pococí. La fruta de este híbrido es de cáscara amarilla (exocarpo o epicarpo) y pulpa anaranjada, con un peso que oscila entre 1 y $1,5 \mathrm{~kg}$, tiene entre 10 y $11^{\circ}$ brix y una firmeza de $85 \mathrm{~N}$ cuando se cosecha con una franja de maduración (Bogantes y Mora, 2006; Bogantes et al., 2011). La semilla fue producida en la Estación Experimental Agrícola Fabio Baudrit Moreno (EEAFBM) de la Universidad de Costa Rica. El almácigo se produjo en la misma EEAFBM en pastillas tipo Jiffy-7 de $41 \mathrm{~mm}$ de diámetro, de turba prensada, deshidratada y esterilizada, de $8 \mathrm{~cm}$ de alto y $5 \mathrm{~cm}$ de ancho, con un volumen de $157 \mathrm{cc}$. Inicialmente, las semillas se pre-germinaron en bandejas cerradas con saturación de humedad, por un periodo de cuatro a seis días, luego las semillas germinadas se sembraron en los contenedores Jiffy, donde permanecieron cinco semanas. La fertilización consistió en 0,3 g de la fórmula 15-15-15 a la siembra y aplicaciones foliares de la fórmula 20-20-20 en una dosis de $5 \mathrm{~g} . \mathrm{l}^{-1}$ de agua cada dos semanas. A la edad de dos semanas, la mitad del almácigo se sometió a un proceso de sexado molecular (SM), realizado en el Laboratorio de Biotecnología de Plantas del Centro de Investigaciones Agronómicas de la Universidad de Costa Rica, según el procedimiento descrito por Saalau et al. (2009). El ADN total se extrajo a partir de segmentos de hoja de $1 \mathrm{~cm}^{2}$ con el método del detergente de Bromuro de cetiltrimetilamonio (CTAB). Para la amplificación mediante PCR se utilizaron los imprimadores desarrollados por Deputy et al. (2002) para amplificar una secuencia específica ligada al sexo de la papaya W11-F (CTGATGGCGTGTGTGGCTCTA) y W11-R (CTGATGCGTGATCATCTACT) de $800 \mathrm{pb}$, y como control interno (independiente del sexo) T1-F (TGCTCTTGATATGCTCTCTG) y T1-R (TACCTTCGCTCACCTCTGCA) de 1300 pb. La mezcla de reacción se realizó en tubos para PCR a un volumen final de $25 \mu 1$, y la amplificación en un termociclador Perkin Elmer GeneAmp PCR System 2400. El programa de termociclado consistió de una temperatura inicial de desnaturalización de $95^{\circ} \mathrm{C}$ por 3 min y 30 ciclos de $60 \mathrm{~s} \mathrm{a} 95$ ${ }^{\circ} \mathrm{C}$ desnaturalización, $90 \mathrm{~s}$ a $58{ }^{\circ} \mathrm{C}$ para alineamiento y 2 min a $72{ }^{\circ} \mathrm{C}$ de extensión, finalmente una extensión de 7 min a $72{ }^{\circ} \mathrm{C}$. Los productos de reacción se separaron en un gel de agarosa al 1,6 \% (p/v), preparado en 0,5X TBE (Tris $10 \mathrm{mM}$, Borato $20 \mathrm{mM}$; EDTA $1,0 \mathrm{mM}$ ) y suplementados con $1 \mu \mathrm{l}$ de bromuro de etidio $\left(10 \mathrm{mg} \cdot \mathrm{ml}^{-1}\right)$. La electroforesis se realizó a $70 \mathrm{~V}$ durante $1,5 \mathrm{~h}$. Las bandas se observaron con luz UV en un transiluminador Kodak EDAS 290. El tamaño de las bandas se verificó con un marcador molecular de referencia (escalerilla) de 100 pares de bases (pb). El patrón de amplificación para plantas hermafroditas consiste de dos bandas de 1300 pb y 800 pb, mientras que para las plantas femeninas de una sola banda de $1300 \mathrm{pb}$. 
La otra mitad del almácigo permaneció sin conocer su condición sexual hasta su determinación en el campo al momento de la floración (sexado convencional, SC). Las plantas permanecieron en la etapa de almácigo durante cinco semanas.

\section{Establecimiento de las plantas en campo}

Se estableció un ensayo con dos tratamientos: plantas sin sexar o sexado convencional (SC) y plantas sexadas molecularmente (SM). En el caso de las plantas SC, se sembraron 216, a una distancia entre plantas y entre lomillos de $2,5 \mathrm{~m}$, en cada punto de siembra se colocaron tres plantas separadas entre sí por $30 \mathrm{~cm}$. A las ocho semanas del trasplante, en el inicio de la floración, se realizó el sexado y se dejó una planta hermafrodita por sitio de siembra. Este procedimiento corresponde al realizado tradicionalmente por el productor de papaya. En los puntos de siembra sin plantas hermafroditas se dejó una planta hembra, para mantener la competencia perfecta entre plantas. Para el caso de las plantas sexadas molecularmente (SM), se sembró una hermafrodita por punto de siembra para un total de 72 plantas. Para una área total del ensayo de $900 \mathrm{~m}^{2}$.

Una vez establecidas las plantas, se siguió el programa de manejo recomendado para producción de papaya en las áreas comerciales, que incluye recomendaciones para la fertilización, el combate de plagas, de patógenos y de otras labores culturales (Bogantes et al., 2011).

\section{Variables evaluadas}

\section{Crecimiento}

Las variables evaluadas fueron la altura de la planta $(\mathrm{en} \mathrm{cm})$, medida con una cinta métrica desde la base del tallo hasta los primordios foliares; el diámetro del tallo (en mm, a $20 \mathrm{~cm}$ del suelo) medido con un vernier digital (electronic digital caliper 0-300 mm). Ambas variables se evaluaron cada dos semanas a partir del trasplante y hasta la semana 30. También se determinó el número de sitios de siembra que solo presentaron plantas femeninas en ambos sistemas de sexado después del sexado, la altura de la primera flor y del primer fruto cuajado (en $\mathrm{cm}$ ) desde el suelo, así como el tiempo (en días) desde el trasplante hasta el cuaje del primer fruto.

\section{Rendimiento y calidad de los frutos}

Para evaluar el rendimiento de las plantas, se determinó el número total de frutos formados en la planta a las 34 semanas después del trasplante. El peso promedio (g) de cada fruto se evaluó a partir de una muestra representativa por repetición de ocho frutos en madurez fisiológica, con una balanza digital de 0-5000 g, en el Laboratorio de Semillas de la Estación Experimental Fabio Baudrit Moreno. Cuando los frutos alcanzaron la madurez visual (color amarillo), se determinó el contenido de sólidos solubles por medio de un refractómetro digital.

A las dieciocho semanas después del trasplante también se determinó la esterilidad femenina. Para ello, se contó el número total de flores en cada axila y el número de flores con ovario. Para calcular la esterilidad femenina se utilizó la fórmula: $\mathrm{EF}=100-\{(\mathrm{nfo} / \mathrm{nft} \mathrm{x} 100)\}$, donde $\mathrm{nfo}=$ número de flores con ovario y nft= número de flores totales. 


\section{Diseño y análisis}

Se utilizó un diseño experimental irrestricto al azar con dieciocho repeticiones, la unidad experimental la constituyeron parcelas de cuatro plantas. Los datos se analizaron con el programa JPM de SAS.

\section{Resultados}

En el sistema SC, el $20 \%$ de los sitios de siembra correspondieron a plantas femeninas aún después de raleo, mientras que, en el SM fue solamente un $2 \%$.

La altura de las plantas sexadas molecularmente $(\mathrm{SM})$ no difirió significativamente $(\mathrm{p}<0,05)$ de la de las plantas de sexado convencional (SC), en ninguna de las edades evaluadas (Figura 1).

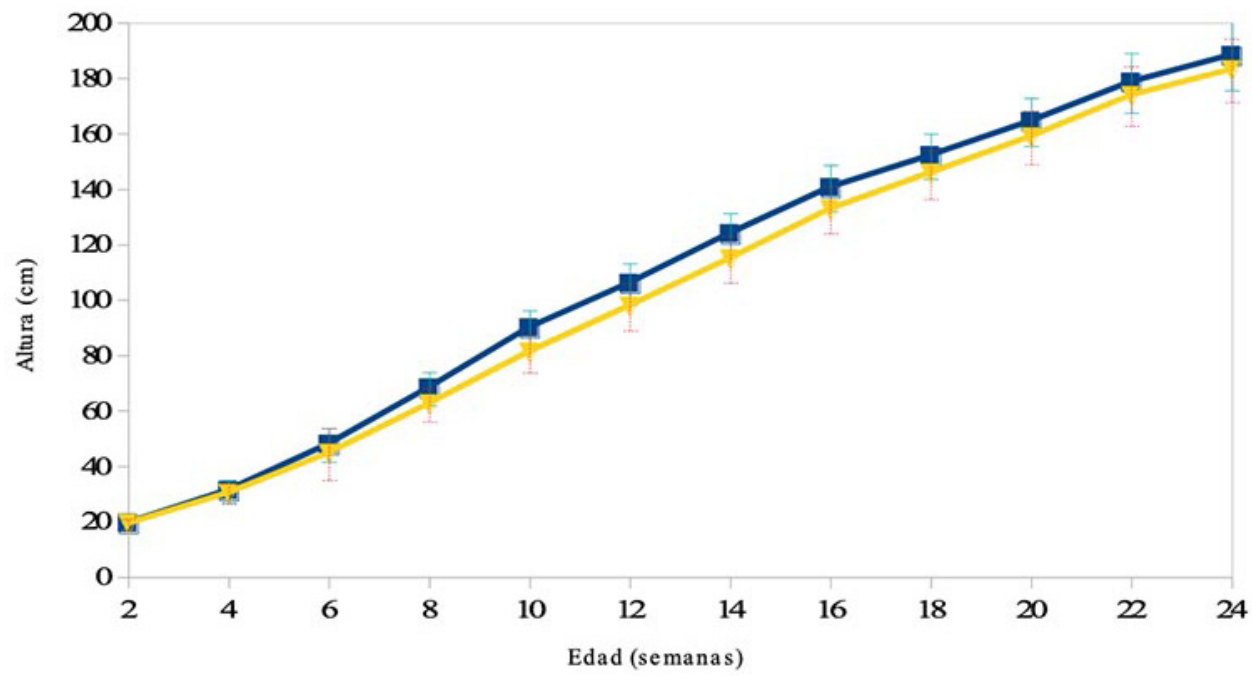

Figura 1. Promedio de la altura de plantas de papaya (Carica papaya L.) híbrido Pococí sexadas mediante los métodos: molecular (línea azul) y convencional, efectuado por el agricultor a las ocho semanas del trasplante, en el inicio de la floración (línea amarilla). La Rita, Pococí, Limón, Costa Rica. 2010.

Figure 1. Average height of papaya plants (Carica papaya L.) Pococi hybrid sexed by the methods: molecular (blue line) and conventional (yellow line), carried out by the farmer eight weeks after transplanting at the beginning of flowering. La Rita, Pococí, Limón, Costa Rica. 2010.

El diámetro del tallo de las plantas tampoco difirió significativamente entre métodos de sexado (Figura 2).

La altura a la primera flor y al primer fruto cuajado fueron significativamente menores $(p<0,05)$ en plantas SM que en plantas SC (Cuadro 1). En ambas variables, las plantas SM presentaron la primera flor y el primer fruto cuajado a menor altura, con una diferencia de $10 \mathrm{~cm}$, aproximadamente. 


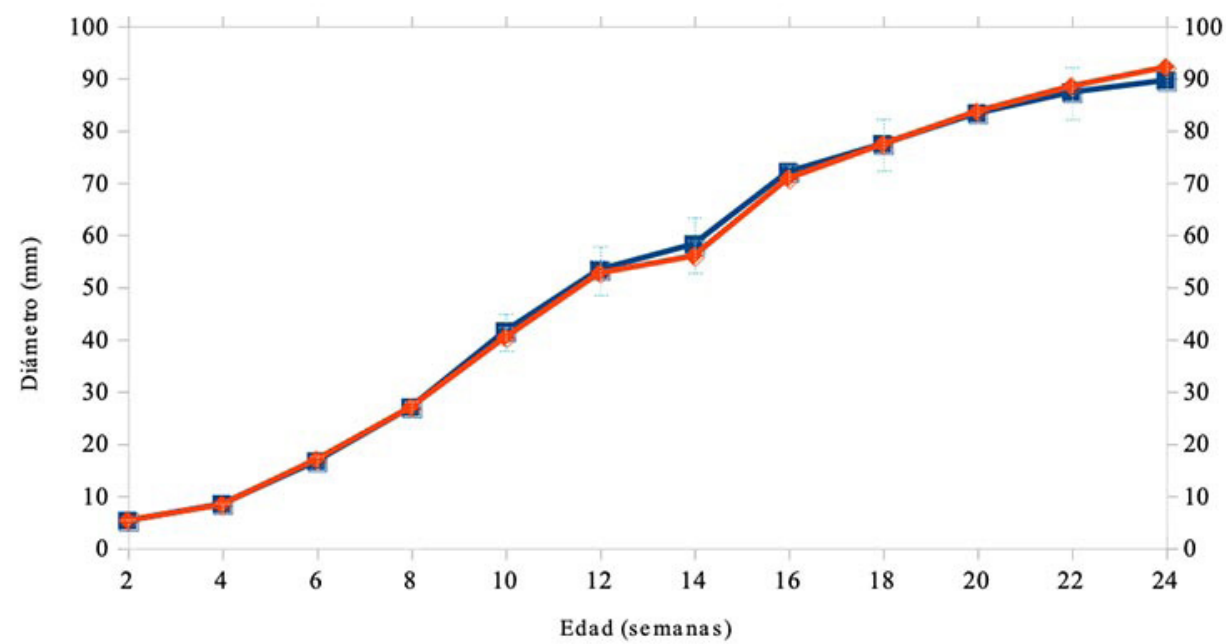

Figura 2. Promedio del diámetro de plantas de papaya (Carica papaya L.) híbrido Pococí sexadas mediante los métodos: molecular (línea azul) y convencional, efectuado por el agricultor a las ocho semanas del trasplante, en el inicio de la floración (línea roja). La Rita, Pococí, Limón, Costa Rica. 2010.

Figure 2. Average in the diameter in plants of papaya (Carica papaya L.) Pococi hybrid sexed by the methods: molecular (blue line) and conventional (red line), carried out by the farmer eight weeks after transplanting at the beginning of flowering. La Rita, Pococí, Limón, Costa Rica. 2010.

Cuadro 1. Altura promedio de la primera flor a las diez semanas de edad y del primer fruto cuajado a las dieciocho semanas en plantas de papaya (Carica papaya L.) híbrido Pococí sexadas mediante los métodos: molecular y el convencional, efectuado por el agricultor a las ocho semanas del trasplante, en el inicio de la floración. La Rita, Pococí, Limón, Costa Rica. 2010.

Table 1. Height average of the first flower at age of ten weeks, and first fruit at age of eighteen weeks in plants of papaya (Carica papaya L.) Pococí hybrid sexed by the methods: molecular and conventional, carried out by the farmer eight weeks after transplanting, at the beginning of flowering. La Rita, Pococí, Limón, Costa Rica. 2010.

\begin{tabular}{lcccc}
\hline & \multicolumn{2}{c}{ Altura de la primera flor $\mathbf{c m})$} & \multicolumn{2}{c}{ Altura del primer fruto cuajado $(\mathbf{c m})$} \\
\cline { 2 - 5 } Método de sexado & Promedio $(\mathbf{c m})$ & DE & Promedio $(\mathbf{c m})$ & DE \\
\hline Molecular & $62,90 \mathrm{a}$ & 4,04 & $89,12 \mathrm{a}$ & 12,88 \\
Convencional & $70,31 \mathrm{~b}$ & 5,16 & $99,08 \mathrm{~b}$ & 14,57 \\
\hline
\end{tabular}

DE: desviación estándar / SD: standard deviation.

Medias seguidas de la misma letra en las columnas no presentaron diferencias estadísticas significativas ( $\mathrm{p} \geq 0,05) /$ Means followed by the same letter in the columns did not show statistically significant difference $(p \geq 0.05)$.

La esterilidad femenina de las plantas tampoco varió entre ambos métodos de sexado (Cuadro 2).

Las plantas de papaya SM y SC no difirieron significativamente en el número de frutos totales, el largo, ancho

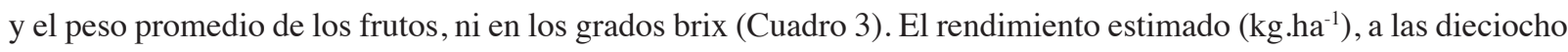
semanas después del trasplante, tampoco difirió entre plantas SM y SC (Cuadro 3). Sin embargo, estos rendimientos variaron para cada tratamiento al considerar solamente los frutos provenientes de plantas hermafroditas. En el caso 
Cuadro 2. Cálculo de la esterilidad femenina de plantas de papaya (Carica papaya L.) híbrido Pococí sexadas mediante los metodos: molecualr y convencional, a las dieciocho semanas de edad. La Rita, Pococí, Limón, Costa Rica. 2010.

Table 2. Calculate of female sterility in plants of papaya (Carica papaya L.) Pococi hybrid sexed by the molecular and conventional methods at age of eighteen weeks. La Rita, Pococí, Limón, Costa Rica. 2010.

\begin{tabular}{|c|c|c|c|c|}
\hline \multirow[b]{2}{*}{ Método de sexado } & \multirow[b]{2}{*}{ Flores con ovario (nfo) } & \multirow[b]{2}{*}{ Flores totales $(n f t)$} & \multicolumn{2}{|c|}{$\begin{array}{c}\text { Esterilidad femenina } \\
\mathrm{EF}=100-\{(\text { nfo/nft } \times 100)\}\end{array}$} \\
\hline & & & Promedio & DE \\
\hline Molecular & $1,61 \mathrm{a}$ & $9,02 \mathrm{a}$ & $18,08 \mathrm{a}$ & 0,03 \\
\hline Convencional & $1,61 \mathrm{a}$ & $8,64 \mathrm{a}$ & $19,08 \mathrm{a}$ & 0,05 \\
\hline
\end{tabular}

DE: desviación estándar / SD: standard deviation.

Medias seguidas de la misma letra en las columnas no presentaron diferencias estadísticas significativas $(\mathrm{p} \geq 0,05) /$ Means followed by the same letter in the columns did not show statistically significant difference $(p \geq 0.05)$.

Cuadro 3. Resultado de la evaluación de los frutos de plantas de papaya (Carica papaya L.) híbrido Pococí sexadas mediante los métodos: molecular y convencional, a las dieciocho semanas de edad. La Rita, Pococí, Limón, Costa Rica. 2010.

Table 3. Results of fruit evaluation in plants of papaya (Carica papaya L.) Pococi hybrid sexed by the methods: molecular and conventional at age of eighteen weeks. La Rita, Pococí, Limón, Costa Rica. 2010.

\begin{tabular}{lcccccc}
\hline Método de sexado & $\begin{array}{c}\text { Longitud } \\
(\mathbf{c m})\end{array}$ & $\begin{array}{c}\text { Ancho } \\
(\mathbf{c m})\end{array}$ & $\begin{array}{c}\text { Peso } \\
(\mathbf{g})\end{array}$ & Grados brix & $\begin{array}{c}\text { Número de } \\
\text { frutos.planta-1 }^{-1}\end{array}$ & $\begin{array}{c}\text { Rendimiento } \\
\left(\mathbf{k g}^{-h} \mathbf{a}^{-1}\right)^{*}\end{array}$ \\
\hline Molecular & $23,31 \mathrm{a}$ & $11,72 \mathrm{a}$ & $1479 \mathrm{a}$ & $10,1 \mathrm{a}$ & $38,3 \mathrm{a}$ & 90633,12 \\
Convencional & $21,77 \mathrm{a}$ & $11,84 \mathrm{a}$ & $1510 \mathrm{a}$ & $9,5 \mathrm{a}$ & $37,7 \mathrm{a}$ & 91083,2 \\
\hline
\end{tabular}

* 1600 plantas.ha-1 / *1600 plantas.ha ${ }^{-1}$.

Medias seguidas de la misma letra en las columnas no presentaron diferencias estadísticas significativas $(\mathrm{p} \geq 0,05) /$ Means followed by the same letter in the columns did not show statistically significant difference $(\mathrm{p} \geq 0.05)$.

del sexado molecular el rendimiento bajó en un $2 \%$ y en el sexado convencional un $20 \%$, que corresponde a las plantas hembras remanentes en las parcelas (SC: 72 866,56 kg.ha- ${ }^{-1}$; SM: 88 811,45 kg.ha-1).

\section{Discusión}

En el presente trabajo, en el sistema convencional el $20 \%$ de los puntos de siembra presentó solo plantas femeninas, lo que cae dentro del rango esperado para el híbrido Pococí, cuando se siembran tres plantas por sitio $(12,5 \%-21,5 \%)$ (Bogantes et al., 2011).

En relación al sistema molecular, el $98 \%$ de los sitios de siembra presentaron plantas hermafroditas, debido posiblemente a la presencia de falsos positivos en el análisis molecular. Para este mismo genotipo y con el mismo método de sexado molecular, Saalau et al. (2009) obtuvieron un $96 \%$ de éxito en la identificación de plantas hermafroditas, lo que indica que el error del método podría variar entre 2 y $4 \%$, y está asociado a error humano, ya que no se observó reversión sexual en el campo. Otros autores (Aspeitia et al., 2014; Salinas et al., 2018), han logrado un $100 \%$ de éxito en la identificación del sexo en diferentes genotipos de papaya y con otros métodos de sexado 
molecular. Por ejemplo, Salinas et al. (2018) utilizaron un método basado en polimorfismos de nucleótido simple (SNPs) y lograron un $100 \%$ de éxito en el sexado de plantas hermafroditas. Esto indica que es posible optimizar el método de sexado molecular y obtener un $100 \%$ de sitios de siembra con plantas hermafroditas. Al contrario, con el sexado convencional se puede presentar una disminución de área productiva entre $12,5 \%$ y $21,5 \%$, es decir, en el mejor de los casos, el SM podría aumentar en un $10 \%$ los puntos de siembra con plantas hermafroditas.

La comparación del crecimiento vegetativo de plantas sexadas molecularmente con plantas sexadas convencionalmente no mostró diferencias significativas entre ambos tipos de sexado. La altura de las plantas SM fue ligeramente mayor al de las plantas SC; pero la diferencia no fue significativa, de manera que la competencia entre plantas, al sembrar tres por punto de siembra, no afectó su crecimiento. Lo anterior evidencia que una distancia entre plantas, en el mismo sitio de siembra, igual o mayor a $30 \mathrm{~cm}$ minimiza los efectos negativos de la competencia entre los individuos adyacentes. Esto durante la etapa anterior al raleo, siempre y cuando este se realice en el tiempo indicado. Así, el raleo a edades muy tempranas, aunado al adecuado manejo de la fertilización y control de enfermedades, previene los efectos negativos de la competencia entre las plantas adyacentes y aquella que permanece presenta un desarrollo vegetativo posterior similar a las plantas sembradas individualmente desde el inicio. Resultados similares fueron obtenidos por Salinas et al. (2018) para el cultivar BH-65 en condiciones de invernadero; estos autores observaron que inicialmente plantas SM fueron $8 \%$ más altas en comparación con plantas SC, sin embargo, tres meses más tarde las plantas sexadas con ambos métodos presentaron casi la misma altura. El diámetro del tallo mostró una tendencia similar a la altura de planta. Resultados similares fueron obtenidos por Salinas et al. (2018) para el cultivar BH-65.

La altura a la primera flor y la altura al primer fruto cuajado no variaron significativamente entre plantas SM y SC, aunque la altura fue aproximadamente $10 \mathrm{~cm}$ menor en plantas SM. Estos resultados fueron similares a los obtenidos por Fitch et al. (2005a) y Salinas et al. (2018); pero la significancia de la diferencia parece depender del genotipo o del número de plantas por sitio de siembra utilizado en el sistema SC. Para el híbrido Rainbow, sembrado a campo abierto y en dos localidades, Fitch et al. (2005a) determinaron que la altura a la primera flor y al primer fruto fue significativamente mayor para plantas SC en comparación con aquellas con SM. En esta ocasión, para el sistema SC se sembraron cinco individuos por sitio de siembra y luego a la floración se dejó una planta hermafrodita (raleo). Mientras que, Salinas et al. (2018), en condiciones de invernadero y con el cultivar BH-65, no encontraron diferencias entre plantas SC y SM para la altura del primer fruto comercial; estos autores sembraron cuatro plantas por sitio de siembra y a la floración dejaron solo una planta hermafrodita.

La esterilidad femenina no varió entre plantas de papaya de ambos métodos de sexado. Consecuencia de un manejo y condiciones ambientales similares para ambos tratamientos. La esterilidad femenina es considerada una estrategia evolutiva que garantiza la sobrevivencia en periodos de estrés, donde se prioriza la reproducción en detrimento de la productividad (Arkle y Nakasone, 1984; Silva et al., 2007). También se ha observado una mayor proporción de frutos malformados, resultado de carpelodia y de la formación de flores petándricas en plantas SM en comparación con plantas SC (Salinas et al., 2018).

El tamaño,forma, dimensiones y número de los frutos por planta en ambos métodos de sexado, correspondieron a los determinados para el híbrido Pococí en la misma zona de estudio (Mora y Bogantes, 2004). No hubo variación entre plantas de ambos métodos de sexado para estas variables. Los resultados obtenidos en el presente estudio coincidieron con lo determinado por Fitch et al. (2005b) para el híbrido Rainbow; pero difirieron de los resultados de Salinas et al. (2018) para el cultivar BH-65, quienes observaron que los frutos de plantas SM presentaron una mayor longitud y diámetro en comparación con frutos de plantas SC.

Los grados brix no difirieron para frutos de papaya de ambos sistemas de sexado. Esto coincide con los resultados de Salinas et al. (2018), quienes establecieron que no existe una relación significativa entre el procedimiento para la determinación del sexo de plantas de papaya para el establecimiento de la plantación y las características cualitativas del fruto tales como color y sabor. Para estos autores, las características fisiológicas de 
los frutos de papaya están predominantemente determinadas genéticamente, aunque la calidad de los frutos puede variar en función de las condiciones y prácticas de cultivo.

El rendimiento estimado por hectárea $\left(\mathrm{kg} \cdot \mathrm{ha}^{-1}\right)$ no difirió entre plantas de papaya híbrido Pococí de ambos sistemas de sexado. Sin embargo, con base en los rendimientos obtenidos (Cuadro 3), y si se considera que en el sistema SC, cuando se siembran tres plantas por punto de siembra, entre un 12,5\% y un 21,5\% de los sitios de siembra es ocupado solo por plantas femeninas, una hectárea sexada molecularmente produciría aproximadamente $16000 \mathrm{~kg}$ más de frutos hermafroditas con respecto al sexado convencional. El efecto del sistema de sexado sobre el rendimiento de plantas de papaya parece depender del genotipo. Para el híbrido Rainbow no se encontraron diferencias significativas para el rendimiento entre plantas SC y SM, en dos localidades en Hawaii (Fitch et al., 2005b), lo que coincide con lo observado en el presente estudio; mientras que, para el cultivar BH-65 el rendimiento comercial de plantas SM fue aproximadamente 49 \% mayor que el de plantas SC (Salinas et al., 2018).

La adopción del SM en la producción de papaya depende de la relación costo-beneficio. Algunos autores (Chaves-Bedoya et al., 2009; Salinas et al., 2018) han estimado que el costo del sexado puede ser compensado por el incremento del rendimiento, con un balance favorable para los productores. Esta información debe ser generada en las condiciones del país.

La combinación del sexado molecular con la micropropagación de plantas hermafroditas podría contribuir a obtener un producto cuyo costo permita su utilización en el establecimiento de plantaciones $100 \%$ hermafroditas (Fitch et al., 2005b).

\section{Conclusiones}

Este estudio evidenció que para el establecimiento de la plantación del híbrido de papaya Pococí, el procedimiento para la determinación del sexo no influyó sobre el crecimiento, desarrollo y rendimiento bajo las condiciones de este estudio. Las variables evaluadas no mostraron diferencias significativas entre plantas sexadas convencional (sistema del productor, SC) y molecularmente (SM),

El método de sexado disminuyó de un $20 \%$ (SC) a un $2 \%$ (SM), el porcentaje de sitios de siembra ocupados solo por plantas femeninas, cuyos frutos son comercialmente no deseados. Esto indica que con sexado molecular es posible establecer plantaciones cercanas a una población $100 \%$ hermafroditas, con el consecuente aumento en el área productiva y la disminución de actividades asociadas a la preparación de almácigos, transporte, mantenimiento en campo de plantas no deseadas y mano de obra en sexado convencional.

Es necesario realizar un análisis de costos para determinar la viabilidad de integrar el sexado molecular en la producción comercial del híbrido de papaya Pococí.

\section{Agradecimientos}

Los autores agradecen a los señores Marcos Corrrales y Francisco Corrales dueños de la finca donde se ubicó el ensayo, y al MSc. Antonio Bogantes por su colaboración en la realizacion de este trabajo.

\section{Literatura citada}

Arkle, T.D., and H.Y. Nakasone. 1984. Floral differentiation in the hermaphroditic papaya. HortSci. 19:823-834.

Aspeitia, V. 2012. Estudio molecular, morfológico y fisiológico de semilla de papaya variedad Maradol (Carica papaya L.).

Tesis MSc., Universidad Autónoma Agraria Antonio Narro, Saltillo, MEX. 
Aspeitia, V., M.A. Torres, D.V. Mendoza, R. Valdés, y M. Humberto. 2014. Evaluación de marcadores genéticos para discriminación entre hembras y hermafroditas de papaya (Carica papaya L.) variedad "Maradol". Rev. Fitotec. Méx. 37:193-197.

Bogantes, A., y E. Mora. 2006. Validación del rendimiento del hibrido de papaya "Pococí" (Carica papaya) en el Caribe de Costa Rica. Rev. Alcances Tecnol. 4(1):53-58.

Bogantes, A., E. Mora, G. Umaña, y C.L. Loría. 2011. Guía para la producción de la papaya en Costa Rica. Ministerio de Agricultura y Ganadería, San José, CRC.

Chaves-Bedoya, G., M. Pulido, E. Sánchez-Betancour, y V. Núñez. 2009. Marcadores RAPD para la identificación del sexo en papaya (Carica papaya L.) en Colombia. Agron. Colomb. 27(2):145-149.

Deputy, J.C., R. Ming, H. Ma, M. Fitch, M. Wang, R. Manshardt, and J.L. Shles. 2002. Molecular markers for sex determinations in papaya (Carica papaya L.) Theor. Appl. Genet. 106:107-111. doi:10.1007/s00122-002-0995-0

Hueso, J.J., I. Salinas, y J. Cuevas. 2015. El cultivo de la papaya. Grupo Cooperativo Cajamar, ESP. https://www. grupocooperativocajamar.es/recursos-entidades/pdf/bd/agroalimentario/innovacion/investigacion/documentos-yprogramas/009-papaya-1441794549.pdf (consultado 9 ago. 2018).

Jiménez, V.M., E. Mora, and M.V. Gutiérrez. 2014. Biology of the papaya plant. In: R. Ming, and P. Moore, editors, Genetics and genomics of papaya. Plant genetics and genomics: Crops and models. Vol 10. Springer, NY, USA. p. 17-34.

Fitch, M.M., P. Moore, T.C. Leong, L.A. Alashi, A.K.F. Yeh, S.A. White, A.S. De-la-Cruz, L.T. Santo, S.A. Ferreira, and L.J. Poland. 2005a. Clonally propagated and seed-derived papaya orchards. I. Plant production and field growth. HortSci. 40:1283-1290.

Fitch, M.M., P. Moore, T.C. Leong, L.A. Alashi, A.K.F. Yeh, S.A. White, A.S. De-la-Cruz, L.T. Santo, S.A. Ferreira, and L.J. Poland. 2005b. Clonally propagated and seed-derived papaya orchards. II. Yield comparison. HortSci. 40:1291-1297.

Mora, E., y A. Bogantes. 2004. Evaluación de híbridos de papaya (Carica papaya L.) en Pococí, Limón Costa Rica. Agron. Mesoam. 15:39-44. doi:10.15517/am.v15i1.11927

Posada, L., R. Gómez, M. León, L. Rojas, e Y. Padrón. 2015. Identificación mediante PCR del sexo de plantas de Carica papaya L. variedad "Maradol Roja” obtenidas vía embriogénesis somática. Biotec. Veg. 15(1):47-51.

Salinas, I., M. Salehi, J.J. Hueso, and J. Cuevas. 2018. Assessment of two sex-determining procedures in 'BH-65' papaya from an economical and developmental point of view. Fruits. 73(3):184-190. doi:10.17660/th2018/73.3.5

Saalau, E., W. Barrantes, C. Loría, A. Brenes, y L. Gómez. 2009. Identificación mediante PCR del sexo de la papaya (Carica papaya L.), híbrido "Pococî”. Agron. Mesoam. 20:311-317. doi:10.15517/am.v20i2.4947.

Sánchez, E., y V.M. Núñez. 2008. Evaluación de marcadores moleculares tipo SCAR para determinar sexo en plantas de papaya (Carica papaya L.). Corpoica Cienc. Tecnol. Agropecu. 9(2):31-36. doi:10.21930/rcta.vo19_num2_art:115

Silva, F.F., P.M. Gonzaga, P.C. Damasceno, P.T. Santana, V.A. Pio, D.R. Filgueiredo, R.H. Cancela, and G.A. Ferrequetti. 2007. Evaluation of the sexual expression in a segregating BC1 papaya population. Crop Breed. Appl. Biotechnol. 7:16-23. doi:10.12702/1984-7033.v07n01a03

Urasaki, N., K. Tarora, T. Uehara, I. Chinen, R. Terauchi, and M. Tokumoto. 2002a. Rapid and highly reliable sex diagnostic PCR assay for papaya (Carica papaya L.). Breed. Sci. 52:333-335. doi:10.1270/jsbbs.52.333

Urasaki, N., M. Tokumoto, K. Tarora, Y. Ban, T. Kayano, H. Tanaka, H. Oku, I. Chinen, and R. Terauchi. 2002b. A male and hermaphrodite specific RAPD marker for papaya (Carica papaya L.). Theor. Appl. Genet. 104:281-285. doi:10.1007/ s001220100693 